\title{
Distribution of Patients Microbial Infections with Cancer Disease of Women
}

\author{
Abdullah Hassan Jassim Abdullah ${ }^{1}$, Kawther Mohammed Ali Hasan², Hawraa Wahab Al-Kaim ${ }^{3}$ \\ ${ }^{1}$ Post Graduate, ${ }^{2}$ Prof., ${ }^{3}$ Assit. Prof. College of Science for Women, University of Babylon, Iraq
}

\begin{abstract}
Cancer disease is a variety of diseases that are uncontrolled development, and non-natural cell disturbance. This can lead to death if the disturbance is not controlled. The results indicate the dangerous role of fungi and bacteria associated with cancer patients.They were both Staphylococcus aureus, Str. mitis, Str. mutans and Escherichia coli are the most common isolates associated with cancer patients. Candida albicans, C. krusei, and C. glabrata are a high frequency yeast and its association with clinical infections indicates the pathogenic role of these yeasts, and the proportions and diversity of fungi were higher in cancer patients compared with healthy ones.
\end{abstract}

Keywords: Fungal infections, Cancer disease, Bloodstream infections.

\section{Introduction}

For most human cancers, it is not possible to determine literally how many individual events are required to bring about all the changes that lead to cancer. It is clear, though, that events, including both mutational changes and promotion, can be caused either by internal or external mechanisms or external events ${ }^{(1)}$.

Breast cancer is the most common malignancy among women, accounting for $29 \%$ of women diagnosed cancer cases. An estimated 2.5 million cases of breast cancer have been recorded in $2016^{(2)}$.Consequently, the etiology of breast cancer remains elusive; the likelihood of cancer development, therapeutic outcomes and survival remain not reliably predictive predictable ${ }^{(3)}$.

Uterus cancer is a malignant tumor that develops from the inner lining of the uterine cavity and is called endometrial cancer. It is the second most common form of cancer among women worldwide, with 170,000 new cases annually being the most prevalent gynecological

\section{Corresponding Author:}

Kawther Mohammed Ali Hasan

Prof., College of Science for Women, University of

Babylon, Iraq

e-mail: kawtherali1972@yahoo.com cancer in developed countries. There are 320000 new cases worldwide per annum ${ }^{(4)}$

The risk of infection in patients with cancer is a function of a balance between the integrity of host defense mechanisms and the intensity of potentially pathogenic exposure to potentially pathogenic microorganisms in the host's environment ${ }^{(5)}$. Whereas alcohol intake, high glycemic diet, higher body mass index, family history of breast cancer, menopause age, and menopausal hormone therapy were risk factors for breast cancer reported ${ }^{(6,7)}$.

The initiation and development of microbiota and chronic inflammation with human ovarian cancer has received little attention ${ }^{(8)}$. Bacteria can have an oncogenic effect on the human cells in three ways: causing chronic inflammation, acting as an antiapoptotic and producing cancerous substances (9). Many fungal infections are caused by Candida spp and Aspergillus spp, and Cryptococcus neoformans, widely known opportunistic fungi, and other fungi of emerging significance have, emerged as major causes of infection in this patient population ${ }^{(10,11,12)}$.

The aim of our study that evaluated the risk factors and their relation to breast and uterus cancer patients, As well as, isolation and identification of pathogenic bacteria and fungi from blood and mouth of women. 


\section{Materials and Method}

Patients: Two hundred samples are collected from 85 women cancer patients (55 breast cancer patients and 30 uterus cancer patients) and 15 control persons attending to Marjan teaching hospital from November 2019 to January 2020. The samples included one hundred blood samples and one hundred swab samples.

Sample collection: This study included collection clinical specimens based on standard method ${ }^{(13,14)}$. The samples collected one hundred samples collected from the oral cavity by swabs with transport media of cancer patients and one hundred samples collected from venous blood stream of cancer patients. As well as control group included 15 blood samples and 15 oral swabs taken from healthy peoples. Cultivation of specimens: For blood specimens tow milliliters of blood were collected from each patient, blood injected directly in glass plain tube which contain $20 \mathrm{ml}$ of BHI (Brain heart Infusion) broth (14). for the purpose of being transferred from the hospital to the laboratory was used cold box to transfer samples. Then incubated blood cultures at $28 \mathrm{C}^{\circ}$ for 7 days. Growth sub-cultured on SDA (Sabouraud's dextrose agar) by streaking and incubate at $28-30 \mathrm{C}^{\circ}$ for $24-48 \mathrm{~h}$ to yeast isolation and 7 days to mold isolates, and cultured on Nutrient agar,Blood Agar base,Salmonella-Shigella agar, mannitol agar and MacConkeyagars for bacteria and incubated at $37 \mathrm{C}^{\circ}$ for $24-48 \mathrm{~h}$.

While for oral cavity specimens were grow pouring and streaking method to get single colonies for fungi cultured on the SDA medium, the Petri dishes were incubated at $28-30 \mathrm{C}$ for $48-72$ hour. After the incubation interval, loop full of single colony growth on SDA and then streaking on CHROMagar and incubated for 24-48 $\mathrm{h}$ at $37 \mathrm{C}^{\circ}$. The isolated colony on CHROMagar have several colors (green, dark pink, pink, white and purple) ${ }^{(15)}$.

\section{Results and Discussion}

Patients and collection of specimens: The results of history and clinical characteristics of cancer patients according to the bacterial and fungal culture results are shown in table (1). The results are shown percentage rate of positive culture in female $70(82.35 \%)$, while negative culture was $41(16.47 \%)$. Although the highest incidence of cancer patients was the age group 41-55 years was 38 cases, also, the highest rate of positive culture in same age group was 32 (37.64\%). When compered between breast and uterus cancer patients according to the culture results, the highest rate of positive culture was in breast cancer cases (84.28\%). Since only one case was associated with not taking chemotherapy and had a positive result with bacterial infection, while 84 cases were associated with taking chemotherapy, including 70 $(82.35 \%)$ cases as a result of positive culture. In breast and uterus cancer patients were 28 cases with chronic diseases, of which 27 (31.76\%), compared to 57 cases without chronic diseases, of which $44(51.76 \%)$. The results of the present study revealed that most of cancer patient duration of incidence for less than 5 years was (42 cases), followed by 5-10 years of duration to incidence was (40 cases), while there is not difference of positive culture products between them was $34(40.0 \%)$.

Table (1): Distribution of history of cancer patients according to the bacterial and fungal culture.

\begin{tabular}{|c|c|c|c|c|c|c|c|}
\hline \multirow{2}{*}{\multicolumn{2}{|c|}{$\begin{array}{l}\text { History of patients } \\
N=100\end{array}$}} & \multicolumn{4}{|c|}{ Positive culture $n=71$} & \multirow{3}{*}{$\begin{array}{c}\begin{array}{c}\text { Negative } \\
\text { culture }(\%) \\
n=14\end{array} \\
/\end{array}$} & \multirow{3}{*}{$\begin{array}{c}\text { Total no } \\
1\end{array}$} \\
\hline & & \multirow{2}{*}{$\begin{array}{c}\begin{array}{c}\text { Bacterial } \\
\text { culture }\end{array} \\
1\end{array}$} & \multirow{2}{*}{$\begin{array}{c}\begin{array}{c}\text { Fungal } \\
\text { culture }\end{array} \\
/\end{array}$} & \multirow{2}{*}{$\frac{\text { Both }}{1}$} & \multirow{2}{*}{$\begin{array}{c}\begin{array}{c}\text { Positive } \\
\text { culture (\%) }\end{array} \\
1(1.17)\end{array}$} & & \\
\hline & Male & & & & & & \\
\hline vender & Female & 38 & 7 & 25 & $70(82.35)$ & $14(16.47)$ & 84 \\
\hline \multirow{4}{*}{ Age } & $26-40$ & 9 & 2 & 1 & $12(14.11)$ & $5(5.88)$ & 17 \\
\hline & $41-55$ & 16 & 3 & 13 & $32(37.64)$ & $6(7.05)$ & 38 \\
\hline & $56-70$ & 11 & 2 & 6 & $19(22.35)$ & $3(3.52)$ & 22 \\
\hline & $71-90$ & 3 & / & 5 & $8(9.41)$ & I & 8 \\
\hline \multirow{2}{*}{ Type } & Breast & 28 & 6 & 19 & $53(62.35)$ & $9(10.58)$ & 62 \\
\hline & Uterus & 11 & 1 & 6 & $18(21.17)$ & $5(5.88)$ & 23 \\
\hline \multirow{2}{*}{ Chemoth. } & Yes & 38 & 7 & 25 & $70(82.35)$ & $14(16.47)$ & 84 \\
\hline & No & 1 & 1 & 1 & $1(1.17)$ & / & 1 \\
\hline
\end{tabular}




\begin{tabular}{|c|c|c|c|c|c|c|c|}
\hline \multirow{2}{*}{\multicolumn{2}{|c|}{$\begin{array}{l}\text { History of patients } \\
N=100\end{array}$}} & \multicolumn{4}{|c|}{ Positive culture $n=71$} & \multirow{3}{*}{$\begin{array}{c}\begin{array}{c}\text { Negative } \\
\text { culture }(\%) \\
\mathbf{n}=\mathbf{1 4}\end{array} \\
1(1.17) \\
\end{array}$} & \multirow{3}{*}{$\begin{array}{c}\text { Total no. } \\
28\end{array}$} \\
\hline & & \multirow{2}{*}{$\begin{array}{c}\begin{array}{c}\text { Bacterial } \\
\text { culture }\end{array} \\
12 \\
\end{array}$} & \multirow{2}{*}{$\begin{array}{c}\begin{array}{c}\text { Fungal } \\
\text { culture }\end{array} \\
3 \\
\end{array}$} & \multirow{2}{*}{$\begin{array}{c}\text { Both } \\
12 \\
\end{array}$} & \multirow{2}{*}{$\begin{array}{c}\begin{array}{c}\text { Positive } \\
\text { culture (\%) }\end{array} \\
27(31.76) \\
\end{array}$} & & \\
\hline & Yes & & & & & & \\
\hline Cnronic D. & No & 27 & 4 & 13 & $44(51.76)$ & $13(15.29)$ & 57 \\
\hline \multirow{3}{*}{ Duration } & $<5$ years & 21 & 5 & 8 & $34(40.0)$ & $8(9.41)$ & 42 \\
\hline & $5-10$ years & 16 & 2 & 16 & $34(40.0)$ & $6(7.05)$ & 40 \\
\hline & $>10$ years & 2 & I & 1 & $3(3.52)$ & / & 3 \\
\hline
\end{tabular}

Several risk factors cause microbial infection in cancer patients and because of the compromised immune system and many other factors these bacterial species cause multiple opportunistic infections in cancer patients ${ }^{(16)}$.Another study by Koll, ${ }^{(17)}$ fungal infections in cancer patients have been a leading cause of morbidity and mortality. One specific challenge with treating such infections is that it is difficult to detect early, so care can be delayed, which also leads to poor clinical outcome. Diverse microbiota is connected to many areas of the human body, such as the gastrointestinal tract, head, and face. The existence of this microbiota, however, is mainly bacteria, fungi, viruses, and there are also Protozoans and Candida spp. they are commensal to safe people and are found the oral mucosa is frequently colonized yeast -caused fungal infection of the genus Candida, oral fungal is the most common humans infected ${ }^{(18)}$.

\section{Isolation and identification:}

Bacterial isolation: In this study, out of total 200 clinical blood samples and oral cavity swabs were isolated from patients with breast cancer and uterine cancer these samples were distributed to control (30), blood (85) and oral cavity swabs (85). From all these samples,) $64 \%$ (were a negative for bacterial growth appeared, while $36 \%$ were positive for bacterial growth appeared. As for the samples taken from blood cancer patients, the percentage of bacterial appearance was $17(8.5 \%)$, while no growth appeared in blood control samples for bacterial culture. In oral cavity swabs was $51(25.5 \%)$ for bacterial growth appeared, while in oral cavity control samples was (2\%). As shown in Table (2) and the Figure (1).

In this study conducted by Nada., ${ }^{(19)}$ reported 107 samples remained from National Cancer Institute (NCI) in Egypt, Seventy two positive cases for bacterial infection are acknowledged. Circulation infection initiated by bacterial pathogens remains a fundamental source of infection and death of cancer patients ${ }^{(20)}$. In a similar study, Twenty patients with the diagnosis of uterine endometrial cancer and 20 patients without complications were enrolled in the study Enterobacteriaceae, Streptococcus agalactiae and anaerobic bacteria were mainlydetected ${ }^{(21)}$.

Table (2): Distribution of specimens type according to bacterial culture results.

\begin{tabular}{|c|c|c|c|c|}
\hline \multicolumn{2}{|c|}{ Specimens type } & Positive culture $(\%)$ & Negative culture $(\%)$ & Total no. (\%) \\
\hline \multicolumn{2}{|c|}{ Blood specimens } & $17(8.5)$ & $68(34.0)$ & $85(42.5)$ \\
\hline \multicolumn{2}{|c|}{ Oral swabs specimens } & $51(25.5)$ & $34(17.0)$ & $85(42.5)$ \\
\hline \multirow{2}{*}{ Control } & Blood s. & 1 & $15(7.5)$ & $15(7.5)$ \\
\hline & Oral s. & $4(2.0)$ & $11(5.5)$ & $15(7.5)$ \\
\hline \multicolumn{2}{|l|}{ Total no. } & $72(36.0)$ & $128(64.0)$ & $200(100)$ \\
\hline
\end{tabular}






Figure (1): Shows total, control, blood and oral samples (positive and nagative samples).

A total number of bacteria colonies is 93 isolated from 200 clinical blood and oral swabs samples taken from breast and uterus cancer patients and healthy controls, the number and percentage of fungi species isolated from clinical samples were summarized in table (3). Seven genera of bacteria are isolated and diagnosed from blood and oral swabs for breast and uterus cancer patients and control individuals. The total number of frequency percentage for bacteria species is $18(19.4 \%)$ isolated from blood samples, while the total number of frequency percentage for oral swabs samples is 67 (72.0\%), compared with total number of frequency percentage for bacteria species isolated from oral swabs control is $8(8.6 \%)$.
During this study, it was isolated many bacterial species from both cancer and control samples were Included: the high frequency rate is Staphylococcus species $(45.1 \%)$ suchas S. aureus $(20.4 \%)$, S. haemolyticus (8.6\%), S. hominis (5.3\%), S. hyicus (4.3\%), S. lentus $(4.3 \%)$ and $S$. equorum (2.2\%). The second frequency rate is Streptococcus species (29\%) such as S. mitis (11.8\%), S. mutans (10.8\%) and S. agalactiae (6.4\%), followed by Escherichia coli (10.8\%), Klebsiella spp (6.5\%), Psudomonas aeruginosa (4.3\%), Enterococcus spp (3.2\%), and Proteus mirabilis (1.1\%), as shown in Table (3) .

Table (3): Distribution of Bacteria species in clinical blood and oral samples of cancer patients and control.

\begin{tabular}{|l|c|c|c|c|}
\hline \multirow{2}{*}{ Fungi species } & \multicolumn{3}{|c|}{ No. of colonies (\%) } & \multirow{2}{*}{ Total no. (\%) } \\
\cline { 2 - 5 } & Blood samples & Oral samples & Oral control & $3(3.2)$ \\
\hline Enterococcus spp & 1 & 2 & - & $10(10.8)$ \\
\hline Escherichia coli & 3 & 5 & - & $6(6.4)$ \\
\hline Klebsiella spp & 2 & 4 & - & $1(1.1)$ \\
\hline Psuedous mirabilis & 1 & - & - & $4(4.3)$ \\
\hline Staphylococcus aureus & - & 4 & - & $19(20.4)$ \\
\hline Sta. equorum & 5 & 14 & - & $2(2.2)$ \\
\hline Sta. haemolyticus & 1 & 1 & - & $8(8.6)$ \\
\hline
\end{tabular}




\begin{tabular}{|l|c|c|c|c|}
\hline \multirow{2}{*}{ Fungi species } & \multicolumn{3}{|c|}{ No. of colonies (\%) } & \multirow{2}{*}{ Total no. (\%) } \\
\cline { 2 - 5 } & Blood samples & Oral samples & Oral control & $5(5.3)$ \\
\hline Sta. hominis & - & 5 & - & $4(4.3)$ \\
\hline Sta. hyicus & 1 & 3 & - & $4(4.3)$ \\
\hline Sta. lentus & - & 4 & 3 & $6(6.4)$ \\
\hline Streptococcus agalactiae & - & 3 & 3 & $11(11.8)$ \\
\hline Str. mitis & - & 8 & - & $10(10.8)$ \\
\hline Str. mutans & - & 10 & $\mathbf{8}(\mathbf{8 . 6})$ & $\mathbf{9 3}(\mathbf{1 0 0})$ \\
\hline Total no. (\%) & $\mathbf{1 8 ( 1 9 . 4 )}$ & $\mathbf{6 7 ( 7 2 . 0 )}$ & & \multicolumn{2}{|c|}{} \\
\hline
\end{tabular}

Nowadays cancer is the second main cause of death in the world. Some specific species have been identified that correlate strongly with cancer, such as Streptococcus sp., Peptostreptococcus sp., Prevotella sp., Fusobacterium sp., Porphyromonas gingivalis, and Capnocytophaga gingivalis .Various bacteria present in various types of cancer patients especially in lung, liver, blood, skin, breast and gastric cancer and different other complication are H.pylori, Mycobacterium tuberculosis, E coli,Streptococcus pyogene, Streptococcus mutant, Staphylococcus aureus ${ }^{(22)}$. Study conducted by Meo, ${ }^{16)}$ isolated bacteria from various varieties of cancer e.g. E coli (14\%), H.pylori (10\%), M. tuberculosis (08\%), Listeria (07\%), S. pyogene (05\%) and S. aureus (05\%). These bacterial species cause different opportunistic infections in cancer patients due to the compromised immune system and many other reasons.

In another study approach to the current study Rolston, ${ }^{(23)}$ investigated gram-positive bacteria isolated from the bloodstream of patients with hematological malignancies were coagulase-negative staphylococci (33\%), Staph aureus $(15 \%)$, viridans group streptococci $(10 \%)$, and the enterococci $(8 \%)$. Velasco, ${ }^{(24)}$ studied that mostly Gram-positive microbes isolated from the circulation of patient with diverse blood cancers such as leukaemia existed coagulase-negative Staphylococci (33\%), the Enterococci (8\%), and viridans group Streptococci (10\%) and Staph aureus (15\%).

While the researcher Iqbal, ${ }^{(25)}$ conducted a study included Clinical blood samples (200) were together from hospitalized cancer and non- cancer patients different bacterial pathogens were identified. Among the isolates $E$ coli were (13.33\%), S. aureus (11.66\%),P. aeruginosa (11.66\%),salmonella (10\%), bacillus spps $(9.16 \%)$, Enterobacter spps $(8.13 \%)$, S. Pyogene (7.5\%), Klebsiella spp. (5.83\%), S. epidermidis (4.16\%) and Shigella were (4.16\%). It has long been known that oral bacteria preferentially colonize different surfaces in the oral cavity as a result of specific adhesions on the bacterial surface binding to complementary specific receptors on a given oral surface ${ }^{(26)}$.

Close to the current study results, Prakash, ${ }^{(27)}$ found Bloodstream Bacterial Pathogens 57.8\% were gram-positive and $42.2 \%$ were gram-negative bacteria. Among the bacterial pathogens, the most common 10 bacterial isolates were: Streptococcus species 76 (21.1\%), coagulase-negative Staphylococci 75 (20.8\%), Escherichia coli (E. coli) 43 (11.9\%) Staphylococcus aureus (S. aureus) 41 (11.4\%), Klebsiella spp. 19 (5.3\%), Streptococcus pneumoniae (S. pneumoniae) 16 (4.4\%), Pseudomonas aeruginosa (P. aeruginosa) and Proteus spp. 11 (3.1\%) each, Salmonella spp. 10 (2.8\%) and Klebsiella pneumoniae (K. pneumoniae) 9 (2.5\%).

Fungal isolation: The results of fungal cultures are summarized in table (4), with 160 specimens from patients with breast and uterus cancer as 85 specimens of blood and 85 specimens of oral swabs as well as 30 specimens from control persons (15 0f blood and 15 of oral swabs). The results of cultures in blood specimens are show $13(6.6 \%)$ in breast and uterus cancer patients have positive culture with fungal infections, whereas in control subjects, the positive culture is zero. In oral swabs samples are show $32(16.0 \%)$ in breast and uterus cancer patients have positive culture with fungal infections, whereas in control subjects, the positive culture is 7 (3.5\%).Significant improvements in the treatment of anticancer have led to increased incidence of serious fungal infections in neoplastic disease patients.

Neutropenia remains one of the most significant predisposing factors associated with the malignancy or its treatment. Some fungal infections are caused 
by Candida spp and Aspergillus spp, widely known opportunistic fungi, and Cryptococcus neoformans, Histoplasma capsulatum, Coccidiodes immitis, and less frequently by Blastomyces dermatidis. Newer pathogens such as Pheohyphomycetes, Hyalohyphomycetes, Zygomycetes and other emerging essential fungi such as Torulopsis glabrata, Trichosporon beigelii, ${ }^{(28)}$.
Cancer patients usually have neutropenia, cellular immune defects and residential catheters which make them an ideal target for fungal infections Several in recent years There has been an rise in cancer centers incidence of difficult infections- to counter opportunistic molds like Fusarium, Zygomycetes, and Scedosporium Species and yeasts for example Trichosporon Species $^{(29)}$.

Table (4): Distribution of specimens type according to fungal culture results.

\begin{tabular}{|c|c|c|c|c|}
\hline \multicolumn{2}{|c|}{ Specimens type } & Positive culture (\%) & Negative culture (\%) & Total no. (\%) \\
\hline \multicolumn{2}{|c|}{ Blood specimens } & $13(6.6)$ & $72(36.0)$ & $85(42.5)$ \\
\hline \multicolumn{2}{|c|}{ Oral swabs specimens } & $32(16.0)$ & $53(26.5)$ & $85(42.5)$ \\
\hline \multirow{2}{*}{ Control } & Blood s. & I & $15(7.5)$ & $15(7.5)$ \\
\hline & Oral s. & $7(3.5)$ & $8(4.0)$ & $15(7.5)$ \\
\hline \multicolumn{2}{|c|}{ Total no. } & $52(26.0)$ & $148(74.0)$ & $200(100)$ \\
\hline
\end{tabular}

A total number of fungi colonies is 124 isolated from 200 clinical blood and oral swabs samples taken from breast and uterus cancer patients and healthy controls, the number and percentage of fungi species isolated from clinical samples were summarized in table (5). Eight species of molds and four species of yeasts are isolated and diagnosed from blood and oral swabs for breast and uterus cancer patients and control individuals. The total number of frequency percentage for fungi species is $41(33.06 \%)$ isolated from blood samples, while the total number of frequency percentage for oral swabs samples is $65(52.41 \%)$, compared with total number of frequency percentage for fungi species isolated from oral swabs control is $18(14.51 \%)$.

During this study, it was isolated many bacterial species fromboth cancer and control sampleswere Included: the high frequency rate is Candida spp. (41.92\%), such asCandida albicans (18.54\%), C. krusei $(12.09 \%)$ and C. glabrata (11.29\%). The second frequency rate is Cladosporium spp. (28.22\%) such as $C$. sphaerospormum (16.93\%) and C. herbarum (11.29\%), followed by Aspergillus spp. (20.95\%), Rhodotorula sp. (3.22\%), Penicillium sp. (2.41\%) and Alternaria sp. $(0.80 \%)$.

Among the 15 species in the list of yeasts Candida that can infect humans, Candida albicans have the highest occurrence last, Candida and Aspergillus species have traditionally accounted for most yeast and mold infections reported in patients with immunocompromised cancer. However, non-Candida yeast, Aspergillus fumigatus, Fusarium spp, Scedosporium spp, Zygomycetes and Phaeohyphomycoses have emerged substantially from various cancer centers around the world in the last decade ${ }^{(30,31)}$. A. fumigatus is the most frequent intrusive source aspergillosis (IA) followed by A. flavus, $A$. terreus, A. niger, A. ustus and A. lentulus. Several cancer centers around the world have reported the emergence of A. niger, A. flavus and A.terreus over the last several years which is assumed to be a result of widespread voriconazole use Prophylaxis in patients with cancer; no- fumigatus of Aspergillus spp. have the available variable susceptibility pattern Antichemicals ${ }^{(32,33)}$.

Table (5): Distribution of Fungi species in clinical blood and oral samples of cancer patients and control.

\begin{tabular}{|l|c|c|c|c|}
\hline \multirow{2}{*}{ Fungi species } & \multicolumn{3}{|c|}{ No. of colonies (\%) } & \multirow{2}{*}{ Total no. (\%) } \\
\cline { 2 - 5 } & Blood samples & Oral samples & Oral control & $1(0.80)$ \\
\hline Alternaria sp. & 1 & $/$ & $/$ & $4(3.22)$ \\
\hline Aspergillus candidus & 1 & 3 & 1 & $13(10.48)$ \\
\hline A. flauvs & 5 & 7 & $/$ & 1 \\
\hline
\end{tabular}




\begin{tabular}{|c|c|c|c|c|}
\hline \multirow{2}{*}{ Fungi species } & \multicolumn{3}{|c|}{ No. of colonies $(\%)$} & \multirow{2}{*}{ Total no. $(\%)$} \\
\hline & Blood samples & Oral samples & Oral control & \\
\hline A. niger & 2 & 3 & 2 & $7(5.64)$ \\
\hline A. terreus & / & 2 & l & $2(1.61)$ \\
\hline Cladosporium herbarum & 5 & 7 & 2 & $14(11.29)$ \\
\hline C. sphaerospermum & 7 & 10 & 4 & $21(16.93)$ \\
\hline Penicillium sp. & 1 & 3 & 1 & $3(2.41)$ \\
\hline White mycelia & 1 & 2 & l & $3(2.41)$ \\
\hline Candida albicanes & 6 & 12 & 5 & $23(18.54)$ \\
\hline C. glabrata & 5 & 7 & 2 & $14(11.29)$ \\
\hline C. krusei & 5 & 8 & 2 & $15(12.09)$ \\
\hline Rhodotorula sp. & 3 & 1 & 1 & $4(3.22)$ \\
\hline Total no. & $41(33.06)$ & $65(52.41)$ & $18(14.51)$ & $124(100)$ \\
\hline
\end{tabular}

Ethical Clearance: The Research Ethical Committee at scientific research by ethical approval of both MOH and MOHSER in Iraq.

\section{Conflict of Interest: None}

Funding: Self-funding

\section{References}

1. Hanahan D, Weinberg R. Hallmarks of Cancer: The next generation. Cell. 2011;144 (5): 646-674.

2. Siegel RL, Miller KD, Jemal A. Cancer statistics, 2016. CA: a cancer journal for clinicians. 2016:66(1), pp.7-30.

3. Parida S, Sharma D. The power of small changes: Comprehensive analyses of microbial dysbiosis in breast cancer. Science Direct. 2019;1871 (2): 392405.

4. Torre LA, Siegel RL, Ward EM, Jemal A. Global cancer incidence and mortality rates and trends- An update. Cancer Epidemiol Biomarkers Prev. 2016; 25 (1): 16-27.

5. Kontoyiannis DP, Rubin RH. Infection in the organ transplant recipient. An overview. Infectious disease clinics of North America, 1995;9(4), p.811.

6. Razzaghi H, Troester MA, Gierach GL, Olshan AF, Yankaskas B, Millikan RC. Association between mammographic density and basal-like and luminal A breast cancer subtypes. Breast Cancer Research, 2013;15: 1-10.

7. Waraztuty I, Siregar KB, Siregar Y. Vitamin
D Receptor Gene TAQ 1 (rs 731236) PolymorphismIn Breast Cancer Patients ATH Adam Malik Hospital Medan and its Relationship with Histopathologygrading. Biomedical Journal of Scientific \& Technical Research (BJSTR), 2018;6(1): 5031-5035.

8. Urbaniak C, Cummins J, Brackstone M, Macklaim JM, Gloor GB, Baban CK, Scott L, O'Hanlon DM, Burton JP, Francis KP, Tangney M. Microbiota of human breast tissue. Applied and environmental microbiology, 2014;80(10): 3007-3014.

9. Holland T, Fowler VG, Shelburne SA. Invasive Gram-Positive Bacterial Infection in Cancer Patients. Clinical Infectious Diseases, 2014;59(5): 331-334.

10. Imran ZK, Abdo Al-Kareem Z. Virulence Compartment Between Clinical And Environmental Candida albicans Isolates . International Journal of Innovation and Applied Studies. 2015;1 (10):563568.

11. Warthe N, Singh SM, Nawange SR, Singh S. Spectrum of Opportunistic Fungal Infections in Cancer/HIV Patients: Emerging Fungal Pathogens from Jabalpur Madhya Pradesh Central India. Sch. J. App. Med. Sci., 2015; 3(3):1385-1390.

12. Peghin M, Monforte V, Martin-Gomez MT, et al. Epidemiology of invasive respiratory disease caused by emerging non-Aspergillus molds in lung transplant recipients. Transpl Infect Dis 2016;18:70-8.

13. Rao PK. Oral candidiasis - A review. Scholarly J. 
International, 2012; 2(2):26-30.

14. Sabeeh S, Al-Attraqhchi AAF, Al-Aswad E. PCR in Comparison with Culture Method for The Diagnosis of Candida albicans Responsible for Candidemia in Leukemic Patient. Diyala Journal of Medicine. 2013;5(2):29-35.

15. Nadeem SG, Hakim ST, kazmi SU. Use of CHROMagar Candida for the presumptive identification of Candida species directly from clinical specimens in resource-limited settings. Libyan J Med, 2010;5: 2144.

16. Meo SA, Suraya F, Jamil B, Al Rouq F, Meo AS, Sattar K, Ansari MJ, Alasiri, SA. Association of $\mathrm{ABO}$ and $\mathrm{Rh}$ blood groups with breast cancer. Saudi journal of biological sciences, 2017;24(7), pp.1609-1613.

17. Koll BS, Brown AE. The changing epidemiology of infections at cancer hospitals. Clinical infectious diseases, 1993;17(2):S322-S328.

18. Khan AA, Khurshid M, Khan S, Alshamsan A. Gut microbiota and probiotics: current status and their role in cancer therapeutics. Drug Development Research, 2013;74(6):365-375.

19. NadaHMA.Ain-ShamsUniversity. Microbiological and Biochemical Studies on certain AntibioticResistant Bacteria Isolated From Certain Clinical Specimens. B. SC. Ain-Shams University. Eygpt, 1999.

20. Eisland DV, Neefjes J. Bacterial infections and cancer. EMBO report 2018; 19:1-11.

21. Mikamo H, Izumi K, Ito K, Watanabe K, Ueno K, Tamaya T. .Endometrial bacterial flora detected in patients with uterine endometrial cancer. Kansenshogaku Zasshi.; 1993;67(8):712-7.

22. Meex P, Melin JD, Docquier $T$, Kabasele $P$, Huynen PM, Tulkens D, Giet P, De Mol. Presence of extended-spectrum beta-lactamase-producing Enterobacteriaceae in the fecal flora of patients from general practice. American Journal of Pharmacology, 2008;54(3) 6-10

23. Rolston KV, Yadegarynia D, Kontoyiannis DP, Raad II, Ho DH. The spectrum of Gram-positive bloodstream infections in patients with hematologic malignancies, and the in vitro activity of various quinolones against Gram-positive bacteria isolated from cancer patients. International journal of infectious diseases, 2006;10(3), 223-230.
24. Velasco E, Byington R, Martins SCA, Schirmer M, Dias LCM, Goncalves VMSC. Bloodstream infection surveillance in a cancer centre: a prospective look at clinical microbiology aspects. Clinical Microbiology and Infectious Diseases, CMI, 2004;10, 542-549.

25. Iqbal A. Comparative analysis of Complete Blood Count in Cancer and Non-Cancer Patients Followed by Antibiogram Analysis of Isolated Bacterial Pathogens. Thesis. Department of Microbiology and Biotechnology, Abasyn University, 2018.

26. Epstein JB, Phillips N, Parry J, Epstein MS, Nevill T, Stevenson-Moore P. Quality of life, taste, olfactory and oral function following high-dose chemotherapy and allogeneic hematopoietic cell transplantation. Bone Marrow Transplantation, 2002;30: 785-792.

27. Prakash KP, Arora V, Geethanjali PP. Bloodstream bacterial pathogens and their antibiotic resistance pattern in Dhahira Region, Oman. Oman medical journal, 2011;26(4):240.

28. Samonis G, Bafaloukos D. Fungal infections in cancer patients: an escalating problem. In Vivo (Athens, Greece), 1992;6(2): 183-193.

29. Mousset S, Buchheidt D, Heinz W, et al.. Treatment of invasive fungal infections in cancer patientsupdated recommendations of the Infectious Diseases Working Party (AGIHO) of the German Society of Hematology and Oncology (DGHO). Ann Hematol, 2014;93:13-32

30. Douglas AP, Chen SC, Slavin MA. Emerging infections caused by non-Aspergillus filamentous fungi. Clin Microbiol Infect. 2016;22: 670-680.

31. Imran ZK,Alshammry ZW. Molecular diagnosis of candidemia of intensive care unite patients based on sequencing analysis of its regions," International J. Pharm Tech Research, 2016; 9(12): 658-668.

32. Slavin M, Van Hal S, Sorrell TC, Lee A, Marriot DJ, Daveson K, et al.. Invasiveinfections due to filamentous fungi other than Aspergillus: epidemiology and determinants of mortality. Clin Microbiol Infect; 2015; 21: 490.

33. Imran ZK, Al.Rubaiy AA. Molecular ecological typing of wild type Aspergillus terreus from arid soils and screening of lovastatin production. Afr. J. Microb. Res. 2015;9(8), 534-542. 